\title{
Definitive treatment of a basal cell carcinoma on the upper lip through the oral
}

\section{administration of Vismodegib}

\author{
Strahil Strashilov ${ }^{1}$, Veselin Kirov², Angel Yordanov³, Vasil Nanev, Ilko Iliev³, and Emil Petkov 5
}

1. Department of Plastic Restorative, Reconstructive and Aesthetic Surgery, Medical University Pleven, Bulgaria

2. Department of Oncodermatology, Medical University Pleven, Bulgaria

3. Clinic of Gynecologic Oncology, Medical University Pleven, Bulgaria

4. Department of Surgical Oncology, Medical University Pleven, Bulgaria

5. Department of Thoracic Surgery, Medical University Pleven, Bulgaria

\section{CASE STUDY}

Please cite this paper as: Strashilov S, Kirov V, Yordanov A, Nanev V, Iliev I, Petkov E. Definitive treatment of a basal cell carcinoma on the upper lip through the oral administration of Vismodegib. AMJ 2018;11(2):78-82.

https://doi.org/10.21767/AMJ.2017.3273

\section{Corresponding Author:}

Angel Danchev Yordanov

Clinic of Gynecologic Oncology, University Hospital "Dr. Georgi Stranski"-Pleven, Georgi Kochev 8A, Bulgaria Email: angel.jordanov@gmail.com

\section{ABSTRACT}

Basal cell carcinoma is the most common malignant neoplasm of the skin of the face in old, caucasian humans. The tumour growth slow and rarely has metastases. The clinical presentation is different. The main method for treating is radical surgical excision, but if the tumour is very big or there are metastases, there is a very effective target therapy with the peroral capsules Vismodegib 150mg. In this case we introduce a patient whit cancer of upper lip of preoperative target therapy whit Vismodegib 150mg, which destroy the tumour cells and help us to make cosmetic surgical excision.

\section{Key Words}

Basal cell carcinoma, vismodegib, target therapy, erivedge

\section{Implications for Practice:}

\section{What is known about this subject?}

The main method for treating basal cell carcinoma is surgical excision with a healthy safety margins.

\section{What new information is offered in this case study?}

The treatment with Vismodegib can be used as preoperative therapy for advanced, primarily difficult to remove basal cell carcinoma.

3. What are the implications for research, policy, or practice?

The treatment with Vismodegib allows surgeons to perform radical excisions in smaller volume with better cosmetic result.

\section{Background}

Basal cell carcinoma is the most common, malignant, neoplastic disease on the skin and in the organism in general. ${ }^{1}$ It accounts for 70 per cent of the keratinocyte cancers. $^{1,2}$ Its frequency is around two per cent of the general population, depending on the latitude and the population age. Most affected are areas of the body, exposed to direct sunlight. The tumour has very slow growth and rarely metastasis.,

Its clinical presentation varies from a nodular formation to a slowly healing ulcer. The main treatment method is a radical surgical excision of the carcinoma. Other surgical and nonsurgical methods are also used.

Here we will present our clinical case of a patient with advanced, primarily difficult to remove basal cell carcinoma on the upper lip, treated with peroral intake of Vismodegib $150 \mathrm{mg}$, followed by a surgical excision. 


\section{Case details}

We present a 54-year-old patient with no accompanying diseases. Around four years ago he noticed a whitish swelling with dilated blood vessels on top of it on his upper lip, left side. The swelling's size was around $0.5 / 0.5 \mathrm{~cm}$. It started growing, and around the end of May 2017, it turned into an ulcer with crusts and elevated, uneven edges, sized around $2.5 / 2.5 \mathrm{~cm}$ (Figure 1 ).

Figure 1: Tumour view before the oral treatment

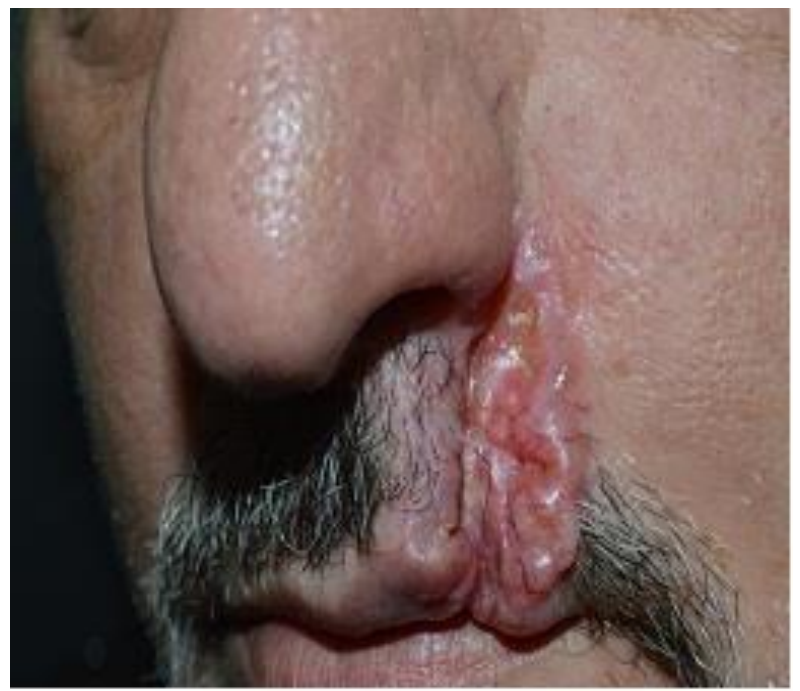

After this change, a consult with a dermatologist was requested, who biopsied the lesion. The histology result was a basal cell carcinoma with multifocal cornification. Disease was staged as T3NOMO (Figure 2).

\section{Figure 2: Histological specimen from the biopsy of the} primary tumour

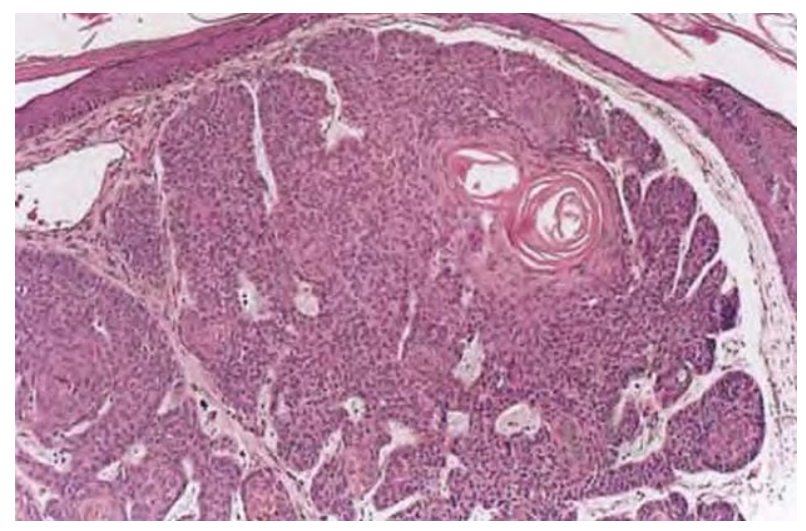

The regional oncology committee, due to the impossibility of a radical excision and bad cosmetic effect in case of a possible primary surgical treatment, decided, in according to the country's medical norms, for a presurgical peroral therapy with Erivedge (Vismodegib) 150mg, one capsule daily for four months.

During the drug therapy patient showed no signs of side effects. During the physical examination at the moment of hospitalization after the end of peroral treatment it was visible that the ulcer with elevated edges had disappeared, and at that spot there was a whitish, dense plaque, size around $1 / 1 \mathrm{~cm}$, looking like a cicatrix (Figure 3 ).

\section{Figure 3: View of the affected site four months after the} oral treatment

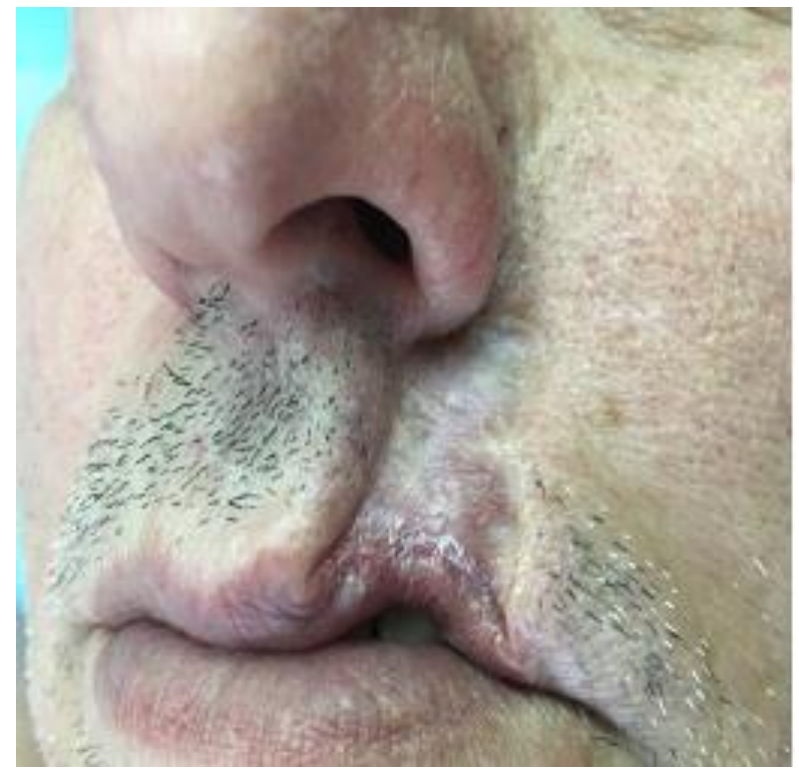

Due to Bulgaria's norms for good medical practice in the complex treatment of the basal cell carcinoma and the patient's cancerophobia, a decision for surgical treatment was made. Under local anaesthesia with 1 per cent Sol. Lidocaini was performed a local wide excision $(2 \mathrm{~mm}$. safety margin) (Figure 4).

Figure 4: Result after local excision of the affected site

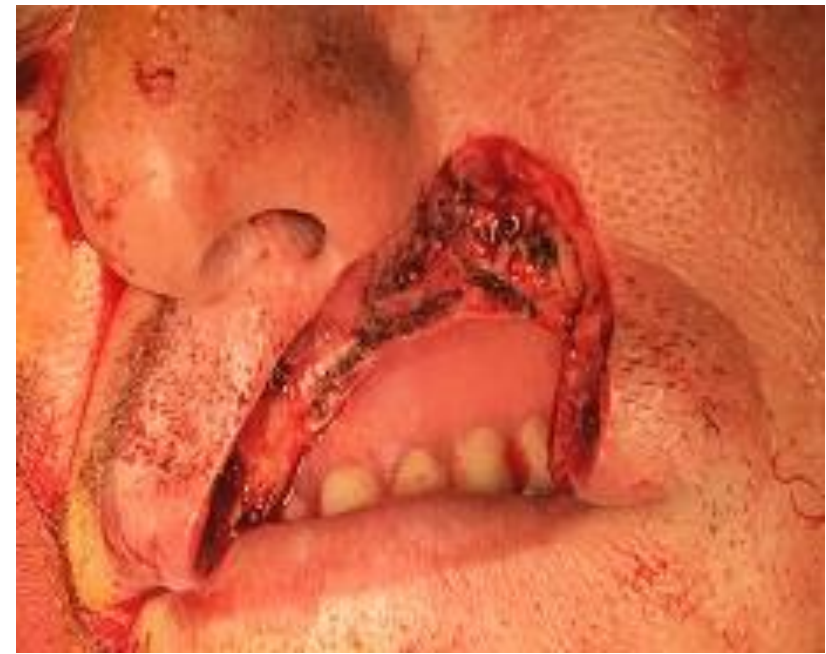


A plastic reconstruction of the upper lip was performed by advanced the musculocutaneous flap after cutting the tissues immediately up to the lateral border of the left nose wing (Figure 5).

\section{Figure 5: Result after the surgical treatment}

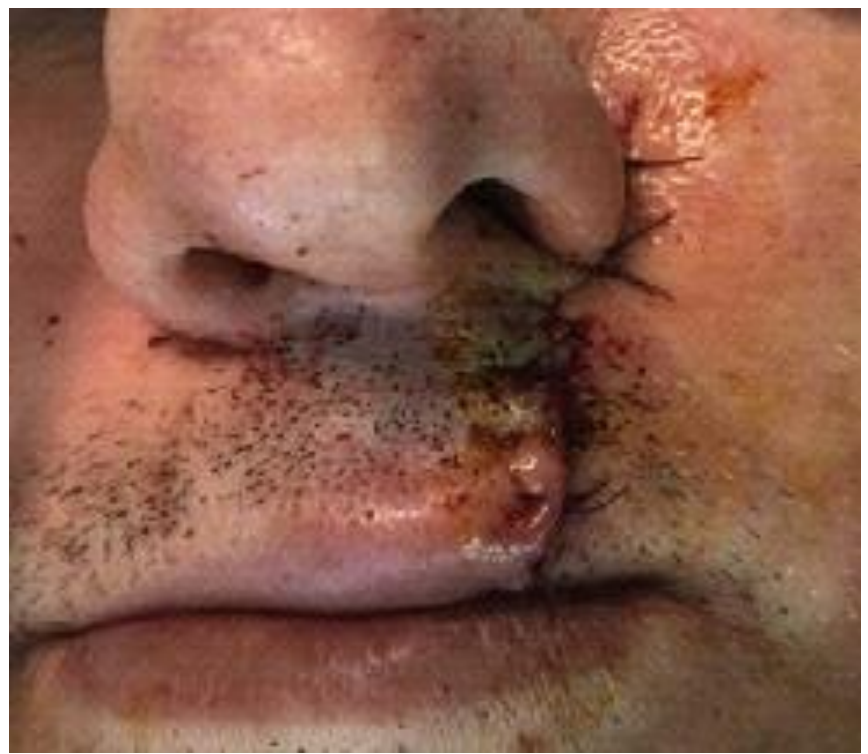

The result of the histopathological examination was: skin and subcutaneous tissue with chronic productive inflammatory process, formation of granulomas with giant cell reaction and lack of tumour cells (Figure 6).

Figure 6: Histological result from surgical excision of the scar, upper lip, after treatment with Vismodegib

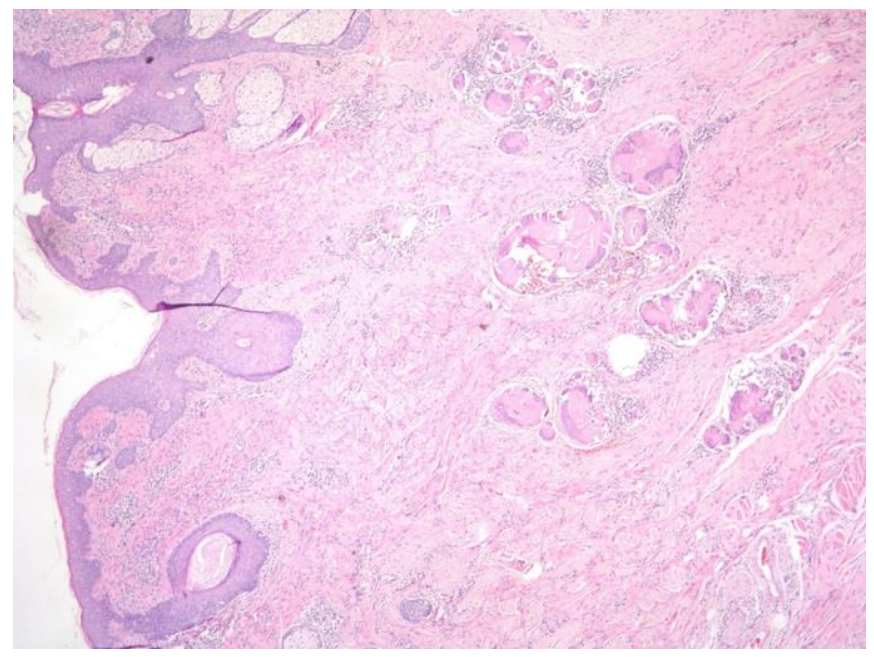

Fourteen days after the intervention the surgical wound is primarily healed and upper lip there was a minimal deformation of the contour of the upper lip (Figure 7).

\section{Figure: 7 Result after removing of the stiches}

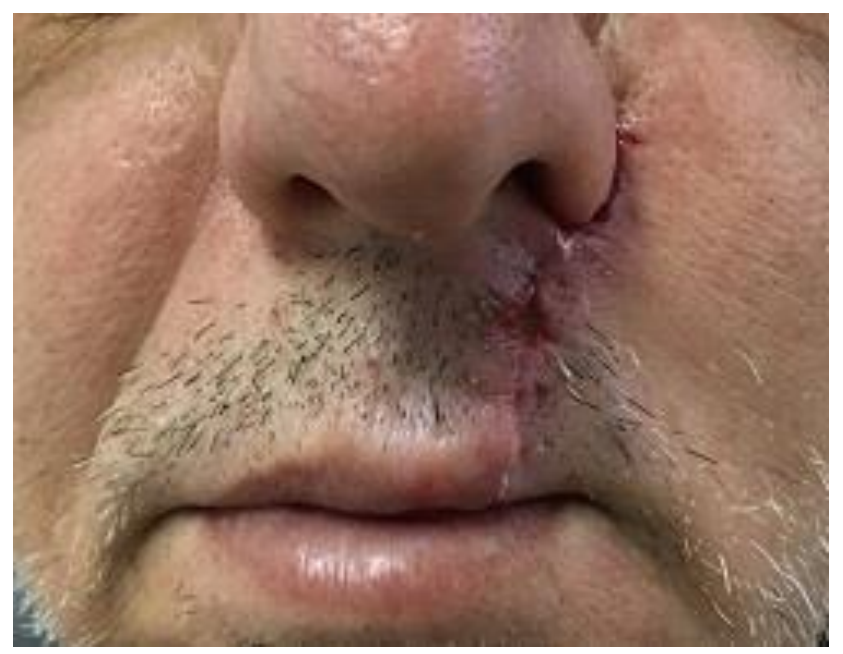

\section{Discussion}

Basal cell carcinoma is the most common malignant neoplasm in humans, with frequency around 2 per cent of the general population. It accounts for 70 per cent of the keratinocyte tumours, which by themselves stand for 90 per cent of all malignant skin diseases. ${ }^{1,2}$ Most affected are caucasian people above the age of 50 . Men are more commonly affected than women. Most affected are areas of the body, exposed to direct sunlight, primarily the face, and in 50 per cent of all cases the nose and cheeks are affected. ${ }^{2}$

Main risk factors for the development of a basal cell carcinoma are: UVB radiation (290-320nm.) ${ }^{5}$ lighter skin; radiotherapy, external exposure to arsenic, immunosuppressive conditions. ${ }^{6}$ The tumour growth is slow and rarely there are distant metastases, but in case of incorrect and delayed treatment leads to the formation of massive progressing ulcers, destroying underlying tissues and disfiguring the affected areas. ${ }^{3,4}$ The clinical presentation of a basal cell carcinoma is usually elevated, shiny part of the skin with pearly nodules and dilated blood vessels above it or an ulcer with elevated edges, often covered with crust and bleeding when touched. Clinical forms are: nodular, cystic, cicatricial, infiltrative, micronodular, superficial, pigmented and fibroepithelioma of Pinkus. $^{7,8}$

Diagnose is confirmed after the histopathological examination of a biopsy material from the suspected lesion.

Main method for the treatment of a basal cell carcinoma is its radical surgical excision, but if the tumour is very small, Mohs surgery is preferred. ${ }^{6}$ The latter was developed in 1938 by the surgeon Frederic Mohs and consists of surgical removal of layers of the tumour skin lesion in a very tight 
margin, with constant histopathological examination of the layers for tumour invasion, until complete radicality is achieved. $^{9,10}$ Other methods for local treatment include cryodestruction, laser therapy and local chemotherapy. Drugs for systemic chemotherapy, immunotherapy and target therapy are also used. ${ }^{11}$

In elderly patients with local advanced, disfiguring or metastatic basal cell carcinoma, which cannot be surgically removed, the target therapy with peroral capsules Vismodegib $150 \mathrm{mg}$ under trade name Erivedge $150 \mathrm{mg}$, one capsule daily for four months, has very good effects. The drug is a small molecule systemic inhibitor of the Hedgehog (Hh) intracellular signalling pathway, which leads to the activation of many genes, participating in the proliferation, survivability and differentiation of cells. Its usage has been permitted in Europe since 12th of July 2013, after which it has been included in a multicentre study of its effectiveness and safety. 1232 elderly patients were included, with locally advanced or metastatic basal cell carcinoma of the skin, and most of them had previously underwent another method for local (excision, radiotherapy) or systemic (chemotherapy) treatment. Complete response was achieved in 4.8 per cent of patients with metastatic and 33.4 per cent of those with locally advanced basal cell carcinoma. Partial response was achieved in 32.1 per cent of patients with metastatic and 35.1 per cent of those with locally advanced basal cell carcinoma. The response was determined after macroscopic and biopsy evaluation of the affected area and observation of the regress of distant metastases through multiple imaging scans. ${ }^{12}$ In that study the result of the preoperative drug use is not separately discussed, and there is scarce medical data about it in literature.

The presented case is about a proven large and ulcerated basal cell carcinoma of the left part of the upper lift, which, upon diagnosing, is unfit for radical surgical treatment, due to its size and location.

Therefore, peroral target therapy with Vismodegib was started, aiming to reduce the tumour size and make it operable. The result was achieved in the end of the 4 month course of the Vismodegib therapy and a surgical treatment was performed. The operation resulted in good cosmetic effect and lack of residual cancer cells, as can be seen from the histological result described above.

\section{Conclusion}

Basal-cell carcinoma of the skin is a socially significant disease due to its high frequency among the human population. Often patients seek medical help too late, when the primary radical surgical treatment is no longer a possibility. In those cases the modern preoperative therapy with Erivedge (Vismodegib) $150 \mathrm{mg}$ is highly beneficial to them - it leads to the reduction of the tumour size and even disappearance of tumour cells from the affected area. This by itself allows surgeons to perform radical excisions in smaller volume with better cosmetic result.

\section{References}

1. Urbach F. Incidence of nonmelanoma skin cancer. Dermatol Clin. 1991;9(4):751-5.

2. Dourmishev A, Popova L, Dourmishev L. Basal-cell carcinoma and squamous-cell carcinomas: epidemiology, location and radiotherapy. Skin Cancer. 1996;11:195-200.

3. Lo JS, Snow SN, Reizner GT, et al. Metastatic basal cell carcinoma: report of twelve cases with a review of the literature. J Am Acad Dermatol. 1991;24(5):715-719.

4. Cakir BÖ, Adamson P, Cingi C. Epidemiology and economic burden of nonmelanoma skin cancer. Facial Plast Surg Clin North Am. 2012;20(4):419-22.

5. Dessinioti C, Antoniou C, Katsambas A, et al. Basal cell carcinoma: what's new under the sun. Photochem Photobiol. 2010;86(3):481-91.

6. Gandhi SA, Kampp J. Skin Cancer Epidemiology, Detection, and Management. Med Clin North Am. 2015;99(6):1323-357.

7. Freedberg I, Eisen A, Wolff $\mathrm{K}$, et al. Fitzpatrick, $\mathrm{s}$ Dermatology in General Medicine. (6th ed.); 2003;856857.

8. James D, Berger $G$, Elston D, et al. Andrews Diseases of the Skin: Clinical Dermatology (10th ed.); 2006;646-650.

9. Basal Cell and Squamous Cell Skin Cancers. National Comprehensive Cancer Network; 2006. pp. BCC-2, BCC3.

10. Dhingra N, Gajdasty A, Neal JW, et al. Confident complete excision of lid-margin BCCs using a marginal strip: an alternative to Mohs' surgery. Br J Ophthalmol. 2007;91(6):794-6.

11.Skin Cancer Treatment. National Cancer Institute. Archived from the original on 4; https://www.cancer.gov/types/skin/hp/skin-treatmentpdq; (21 June 2017)

12. Basset-Seguin N, Hauschild A, Grob JJ, et al. Vismodegib in patients with advanced basal cell carcinoma (STEVIE): a pre-planned interim analysis of an international, openlabel trial. Lancet Oncol. 2015;16(6):729-36.

\section{PEER REVIEW}

Not commissioned. Externally peer reviewed. 


\section{CONFLICTS OF INTEREST}

The authors declare that they have no competing interests.

\section{FUNDING}

None

\section{PATIENT CONSENT}

The authors, Strashilov S, Kirov V, Yordanov A, Nanev V, Iliev I, Petkov $E$, declare that:

1. They have obtained written, informed consent for the publication of the details relating to the patient(s) in this report.

2. All possible steps have been taken to safeguard the identity of the patient(s).

3. This submission is compliant with the requirements of local research ethics committees. 